\title{
A Quantitative Assessment of Surface Urban Heat Islands Using Satellite Multitemporal Data over Abeokuta, Nigeria
}

\author{
K. A. Ishola, E. C. Okogbue, and O. E. Adeyeri \\ Department of Meteorology and Climate Science, Federal University of Technology, PMB 704, Akure, Ondo State, Nigeria \\ Correspondence should be addressed to K. A. Ishola; skorchie126@yahoo.com
}

Received 5 November 2015; Revised 29 March 2016; Accepted 5 April 2016

Academic Editor: Dimitris G. Kaskaoutis

Copyright (c) 2016 K. A. Ishola et al. This is an open access article distributed under the Creative Commons Attribution License, which permits unrestricted use, distribution, and reproduction in any medium, provided the original work is properly cited.

\begin{abstract}
The fast urban expansion has led to the transformation of the natural landscape into anthropogenic surfaces. The city of Abeokuta, for instance, is located in a region experiencing rapid urbanization, which has produced a remarkable effect on the surface thermal response. This effect significantly influences urban internal microclimatology on a regional scale. In this study, the surface temperatures and land cover types retrieved from Landsat TM and ETM+ images of Abeokuta city for 1984, 2003, and 2014 were analyzed. A quantitative approach was used to assess surface urban heat islands through the relationships among surface temperature and land cover types. Results showed that impervious surface areas were found to be correlated positively with high temperatures. Conversely, vegetated areas and bare surfaces correlated positively with mid temperature zones. This study found that areas with increasing impervious surfaces will accelerate LST rise and consequently lead to increasing effect of surface urban heat islands. These findings pose a major challenge to urban planners. However, the study would help to quantify the impacts of different scenarios (e.g., vegetation loss to accommodate urban growth) on LST and consequently to devise appropriate policy measures.
\end{abstract}

\section{Introduction}

Rapid rural-urban migration and population growth in the cities over the past decades have led to an unprecedented rate of urbanization globally, and it is likely to continue in the subsequent decades [1]. During the process of urbanization, a direct environmental consequence is the modification of land surfaces which results in the alteration of its physical properties including soil moisture, material heat capacity, and surface reflectivity and emissivity. This leads to change in land surface temperature and the decrease of evapotranspiration [2]. Consequently, the impacts result in surface urban microclimate variations locally. Over the last three decades, the rapid development of remote sensing techniques provided appropriate data for studying the regional surface characteristics of an area. Land surface parameters such as land surface temperature (LST), the normalized difference vegetation index (NDVI), and surface albedo dynamics were derived from data obtained from these sensors [3]. A quantitative relationship between LST and land use/land cover using both empirical and dynamic numerical methods has been documented $[4,5]$.
The consistent expansion of the urban areas is evident in the transformation of natural landscape into anthropogenic impervious surfaces. In turn, increased impervious surface areas also lead to greater temperatures in urban areas than in nonurban areas resulting in urban heat effect [6]. The proportion of impervious surfaces has been reported to be a good indicator for the monitoring of the urban thermal response. A positive correlation between the proportion of impervious surfaces and land surface temperatures was identified by Yuan and Bauer [7].

However, a consistent and quantitative detailed study to assess the changes in surface thermal response due to urban sprawl in Abeokuta city is very rare. This is probably due to the challenges of lack of consistent and repetitive data coverage on the changes in land surface physical conditions over this area. Hence, this study is aimed at assessing quantitatively the changes in surface urban thermal response due to various heterogeneous surface areas. The study will evaluate the dynamics of LST with respect to land cover changes and also determine the separate contributions of land cover types to surface thermal response change. Further, it will assist urban planners and policy makers in developing 


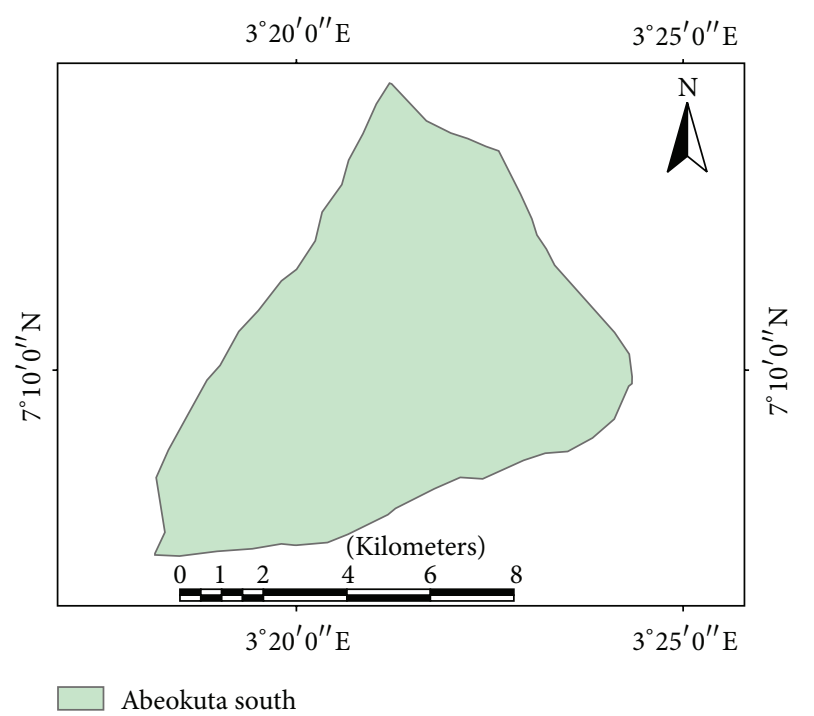

Figure 1: Map showing the study area.

measures to curbing the environmental risks posed by this impact.

\section{Materials and Methods}

This study looks at the city of Abeokuta in southwest Nigeria (Figure 1) due to its rapid human and industrial growth and development. It lies between latitudes $7^{\circ} 10^{\prime} 0^{\prime \prime} \mathrm{N}$ and $7^{\circ} 15^{\prime} 0^{\prime \prime} \mathrm{N}$ and longitudes $3^{\circ} 17^{\prime} 0^{\prime \prime} \mathrm{E}$ and $3^{\circ} 26^{\prime} 0^{\prime \prime} \mathrm{E}$. Annual rainfall is about $963 \mathrm{~mm}$ and the temperature is usually between 26 and $28^{\circ} \mathrm{C}$. The study employs cloudless Landsat $5 \mathrm{TM}$ and 7 ETM+ images from 18 December 1984, 29 January 2003, and 29 December 2014. All bands from the images were applied in the analysis. Bands 1-5 and 7 have a spatial resolution of $30 \mathrm{~m}$, and the thermal infrared band (band 6) has a spatial resolution of $120 \mathrm{~m}$.

2.1. Land Cover Classifications. The maximum likelihood scheme was adopted for this work. Based on the prior knowledge of the land cover types in the study area, a chosen color composite $(\mathrm{RGB}=432)$ was used for digitizing polygons around each training site for similar land cover. Then a unique identifier was assigned to each known land cover type. Afterwards, the statistical characterizations (i.e., signatures) of each land cover class were developed. Each composed image was ordered into 4 area classes: water, vegetation, impervious surface, and bare soil as shown in Figure 2.

2.2. Image Processing. The images acquired from the United States Geological Survey (USGS) database were radiometrically corrected before the calculation to avoid a datasetspecific result. The radiometric correction employed the algorithm of Chander and Markham [8] with the addition of an atmospheric correction.
This converted the digital number $(\mathrm{DN})$ of the raw image to at-satellite reflectance. Thermal band 6 was converted to atsatellite temperature and then corrected in an emissive way to LST. The LST was retrieved using the following models:

$$
\begin{aligned}
T_{b} & =\frac{K_{2}}{\ln \left[\left(K_{1} / L_{\lambda}\right)+1\right]}, \\
\text { LST } & =\frac{T_{b}}{\varepsilon_{0}^{0.25}},
\end{aligned}
$$

where $L_{\lambda}$ equals spectral radiance at the sensor's aperture $\left(\mathrm{w} / \mathrm{m}^{2} *\right.$ ster $\left.* \mu \mathrm{m}\right) ; T_{b}$ equals brightness temperature $(\mathrm{K}) ; K_{1}$ and $K_{2}$ equal calibration constants. $K_{1}$ equals 607.76/666.09 and $K_{2}$ equals $1260.56 / 1282.71\left(\mathrm{Wm}^{-2} \mathrm{sr}^{-1} \mu \mathrm{m}^{-1}\right)$ for Landsat $5 / 7 ; \varepsilon_{0}$ equals surface broadband emissivity; LST equals land surface temperature $(\mathrm{K})$.

\section{Results and Discussion}

Surface temperature has been established as a major indicator of the presence of surface urban heat island in cities and urban areas. The relationship between land cover and surface temperature was analyzed for each year by producing images that provided a visual resource for analyzing the intensity and spatiality of LST change.

3.1. Spatiotemporal Dynamics of LST. The spatial-temporal distributions of LST changes over Abeokuta in the three examined dates (Figure 3) show that the LSTs ranged from $25.0^{\circ} \mathrm{C}$ to $37.9^{\circ} \mathrm{C}, 18.6^{\circ} \mathrm{C}$ to $34.4^{\circ} \mathrm{C}$, and $23.7^{\circ} \mathrm{C}$ to $40.2^{\circ} \mathrm{C}$ in 1984,2003 , and 2014, respectively.

Figure 4 shows that no areas in Abeokuta experienced an extreme temperature $\left(\geq 41^{\circ} \mathrm{C}\right)$ as at the time satellite overpassed in all the periods. In 1984, a large part of the area $(67.7 \%$ in all) fell within the higher temperature zones $\left(\geq 30^{\circ} \mathrm{C}\right)$ and other areas $(32.3 \%)$ fell into mid temperature zones $\left(25^{\circ} \mathrm{C}-30^{\circ} \mathrm{C}\right)$. This high surface temperature might be due to high insolation and few atmospheric compositions (like the cloud cover) as at the time satellite overpassed, large distribution of imperviousness, or geographical relief of the area.

But in 2003, about $66.3 \%$ proportions of the surface area were dominated by mid-surface temperature zones $\left(25^{\circ} \mathrm{C}-30^{\circ} \mathrm{C}\right)$. Other surface areas $(29.1 \%$ and $4.6 \%)$ fell in the lower $\left(<25^{\circ} \mathrm{C}\right)$ and higher $\left(\geq 30^{\circ} \mathrm{C}\right)$ temperature zones, respectively. Moreover, a higher LST zone $\left(\geq 30^{\circ} \mathrm{C}\right)$ was also observed in majority ( $81.6 \%)$ of the area in 2014 . A noticeable surface area proportion $(0.3 \%$ and $18.2 \%)$ were found in the lower $\left(<25^{\circ} \mathrm{C}\right)$ and mid $\left(25^{\circ} \mathrm{C}-30^{\circ} \mathrm{C}\right)$ temperature zones, respectively (Figure 4 ).

The mean surface temperature variation over different land cover types (Figure 5) showed that the majority of the bare soil and impervious surface areas of Abeokuta had temperatures between $32^{\circ} \mathrm{C}$ and $35^{\circ} \mathrm{C}$ in both 1984 and 2014 . In 2003 , the temperature was cooler between $26^{\circ} \mathrm{C}$ and $29^{\circ} \mathrm{C}$ in both land cover types.

However, vegetation and water bodies have similar temperature variations between 28 and $30^{\circ} \mathrm{C}$ in 1984 and 2014 . 


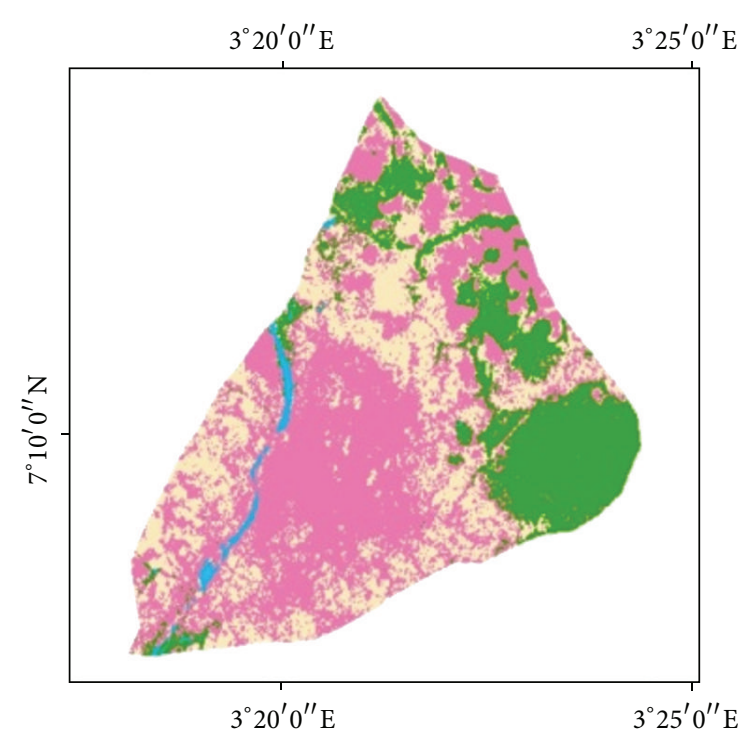

(a) $3^{\circ} 20^{\prime} 0^{\prime \prime} \mathrm{E}$

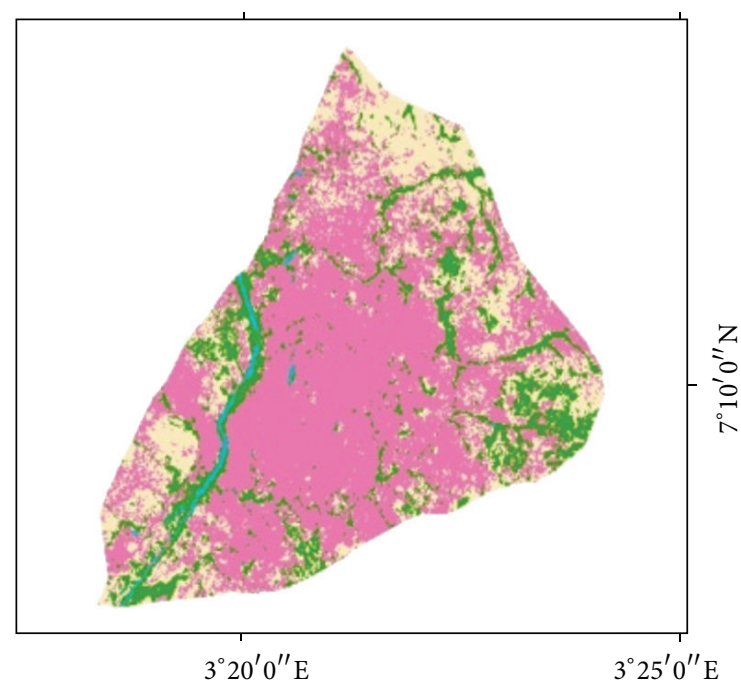

(b)

$3^{\circ} 20^{\prime} 0^{\prime \prime} \mathrm{E}$

$3^{\circ} 25^{\prime} 0^{\prime \prime} \mathrm{E}$

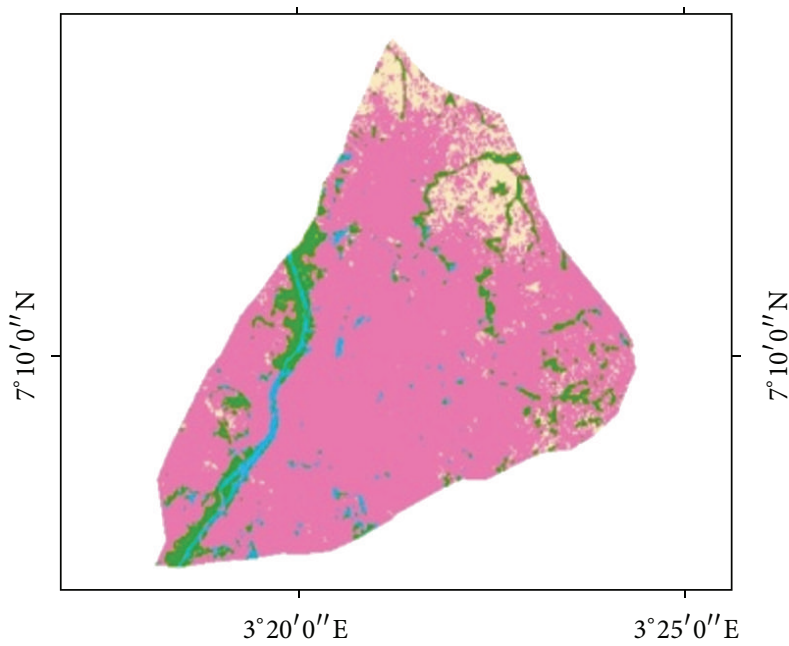

LULC

Class names

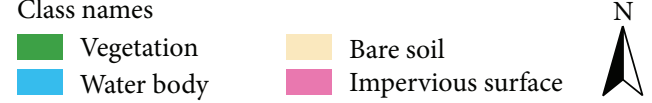

Coordinate system: WGS 1984 UTM Zone 31N

Projection: Transverse Mercator Central meridian: 3.0000

Datum: WGS $1984 \quad$ Scale factor: 0.9996

False easting: 500,000.0000 Latitude of origin: 0.0000

False northing: $0.0000 \quad$ Units: meter

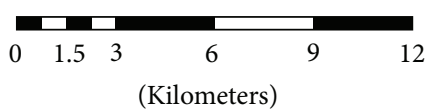

(c)

Figure 2: Maps of land cover types of Abeokuta city for (a) 1984, (b) 2003, and (c) 2014.

This could be attributed to less urbanization process in the former year and increase in population and infrastructural development which has led to the extension of the urban core (higher urbanization) into the adjoining rural lands in the later year. Moreover, the mean LSTs of vegetation cover and water bodies were taken to between $24^{\circ} \mathrm{C}$ and $26^{\circ} \mathrm{C}$ in 2003 which might be due to the presence of cloud cover and aerosol loads that reduced the incoming shortwave 


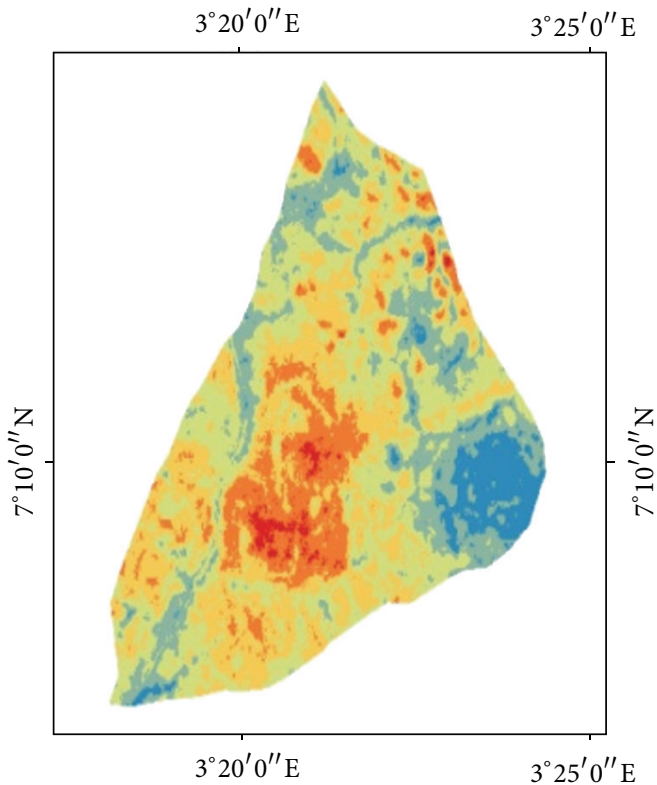

(a)

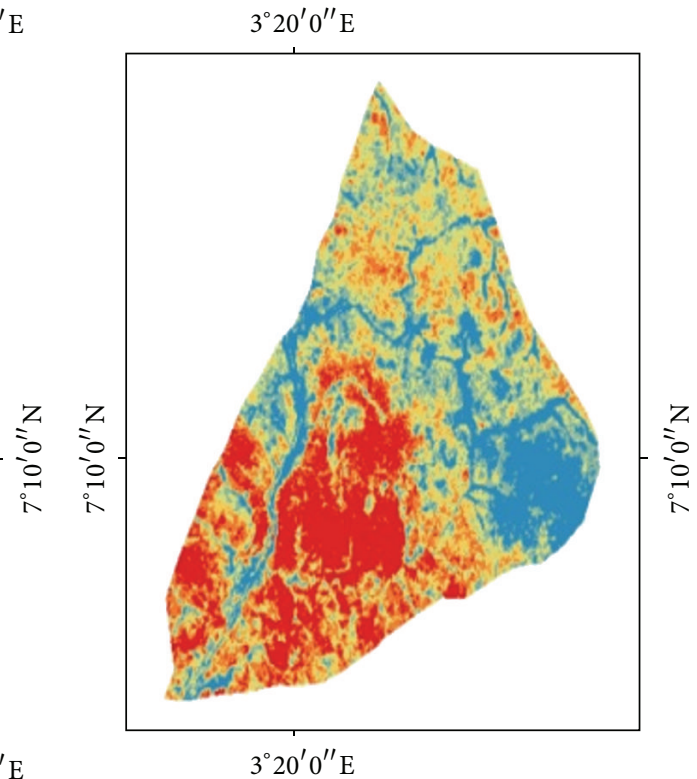

(b)

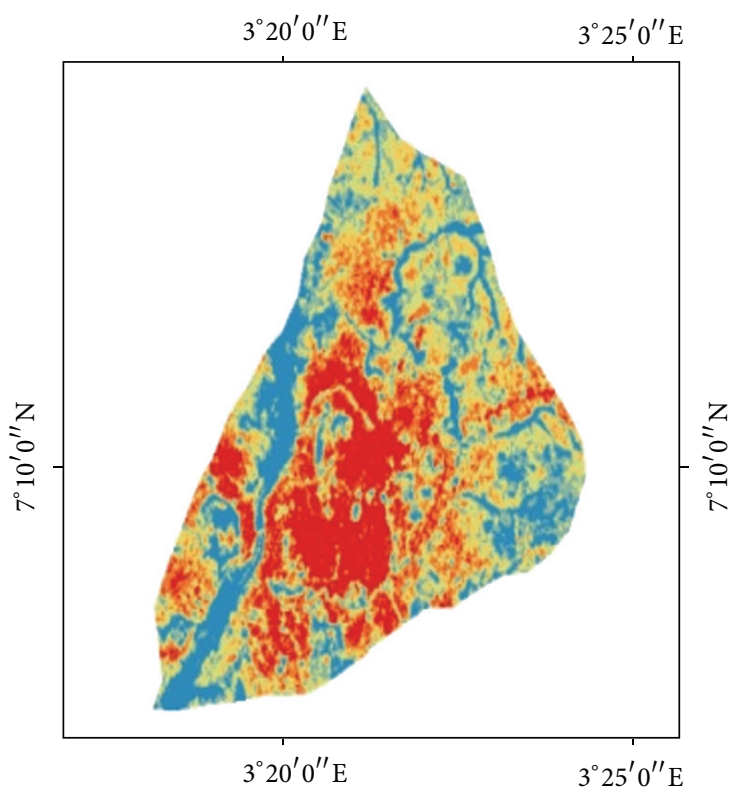

LST (degree Celsius)

\begin{tabular}{|l|l|l|l|}
\hline$<29$ & $33-35$ \\
$29-31$ & $35-37$ \\
$\square$ & & \\
$31-33$ & $\geq 37$
\end{tabular}

Projection: Transverse Mercator Central meridian: 3.0000

Datum: WGS 1984

Scale factor: 0.9996

False easting: 500,000.0000 Latitude of origin: 0.0000

False northing: 0.0000

Units: meter

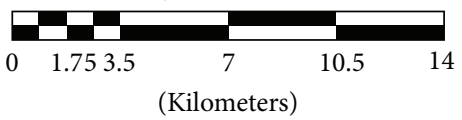

(c)

FIgURE 3: Maps of Abeokuta city showing the thermal zones for (a) 1984, (b) 2003, and (c) 2014. 
TABLE 1: Correlations among LSTs and land cover types.

\begin{tabular}{|c|c|c|c|c|c|c|c|c|}
\hline & ISA & Bare & Veg. & Water & $<25^{\circ} \mathrm{C}$ & $25-30^{\circ} \mathrm{C}$ & $30-33^{\circ} \mathrm{C}$ & $\geq 33^{\circ} \mathrm{C}$ \\
\hline ISA & 1.00 & -0.99 & -0.99 & 0.92 & -0.22 & -0.50 & -0.10 & 0.78 \\
\hline Bare & & 1.00 & 0.97 & -0.96 & 0.34 & 0.60 & -0.02 & -0.85 \\
\hline Veg. & & & 1.00 & -0.86 & 0.10 & 0.39 & 0.23 & -0.70 \\
\hline Water & & & & 1.00 & -0.59 & -0.80 & 0.30 & 0.97 \\
\hline$<25^{\circ} \mathrm{C}$ & & & & & 1.00 & 0.96 & -0.95 & -0.78 \\
\hline $25-30^{\circ} \mathrm{C}$ & & & & & & 1.00 & -0.81 & -0.93 \\
\hline $30-33^{\circ} \mathrm{C}$ & & & & & & & 1.00 & 0.54 \\
\hline$\geq 33^{\circ} \mathrm{C}$ & & & & & & & & 1.00 \\
\hline
\end{tabular}

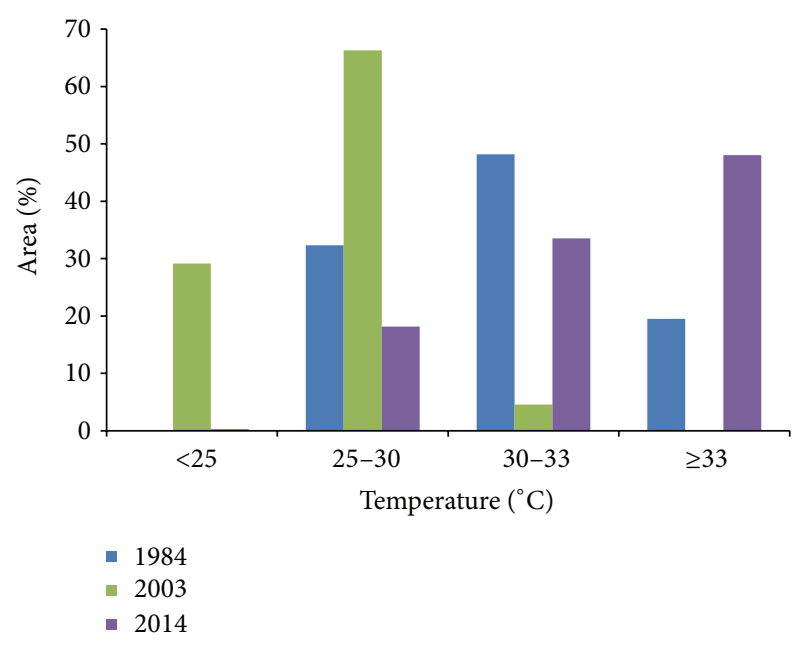

FIGURE 4: Changing pattern of surface temperature zones.

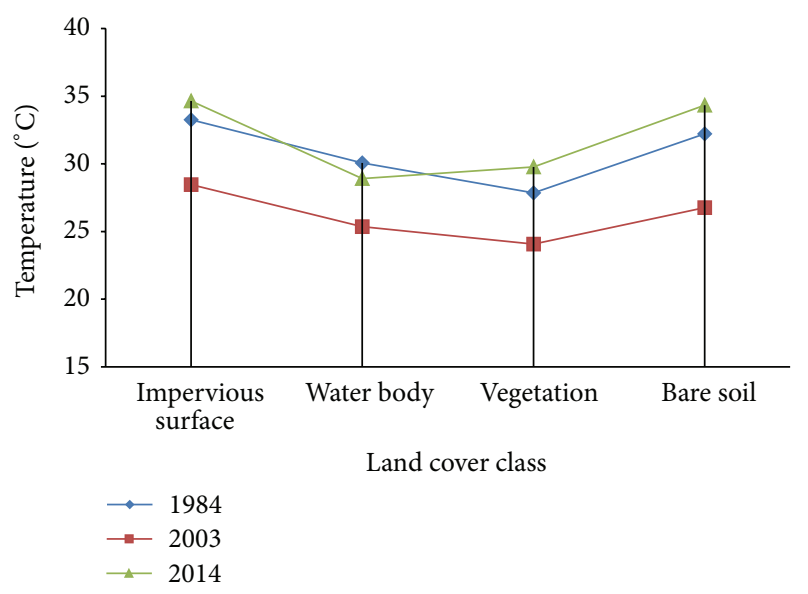

FIGURE 5: Mean LST variations over different land cover types.

radiation. The high surface temperature even over vegetation cover in 2014 was as a result of more surface modifications, anthropogenic activities, little vegetation, and consequently little/no evapotranspiration. In addition, the magnitude of LST change is almost the same $\left(5-6^{\circ} \mathrm{C} / 16-19\right.$ years $)$ over both impervious surface and bare soil (Figure 5).
3.2. Quantitative Relationship between LST and Land Covers. To show a quantitative relationship between land covers and temperature change, the study used the Pearson Correlation to calculate the correlation matrix (Table 1). The area size data extracted from the supervised classification for each year was analyzed using the R software environment for statistical computing [4]. The higher positive correlations were found between the ranges of temperature $<25^{\circ} \mathrm{C}$ and $25-30^{\circ} \mathrm{C}$ and high temperature of $30-33^{\circ} \mathrm{C}$ and $\geq 33^{\circ} \mathrm{C}$. The highest negative correlations were found between the temperature range of $<25^{\circ} \mathrm{C}$ and $30-33^{\circ} \mathrm{C}$ and the higher temperature ranges (25$30^{\circ} \mathrm{C}$ and $\geq 33^{\circ} \mathrm{C}$ ).

A high negative correlation was also found between the $25-30^{\circ} \mathrm{C}$ and $30-33^{\circ} \mathrm{C}$ temperature range. The higher positive correlation between land covers was found between areas of vegetation and bare soil and high correlation between impervious surface area (ISA) and water bodies. The highest negative correlation was between ISA and vegetated and ISA and bare areas.

To relate the land cover patterns to surface urban heat, the correlations between the classes of land cover and LST were analyzed (Table 1). The best highest positive correlations were found between water, ISA areas, and temperatures $\geq 33^{\circ} \mathrm{C}$.

These findings were consistent with $[6,7]$. Other positive correlations were found between bare areas and temperatures between 25 and $30^{\circ} \mathrm{C}$. However, these correlations were not as high compared to what was found in ISA and water areas.

The highest positive correlations with low temperatures were found in the classes of bare soil and vegetation. Conversely, vegetation and bare areas had a high negative correlation with high temperatures.

As shown in Figures 2 and 4 and Table 1, changes in land cover patterns are highly correlated to changes in LSTs and the surface urban heat island (SUHI) effect.

The impervious surface and water areas were found to contribute positively to LST rise, averagely through the three examined dates, with percentage contributions of moderate $60 \%$ to high $90 \%$ (Figure 6). Consequently, this might lead to SUHI effect because the growth of impervious surfaces coincided with an increase in temperatures. However, vegetation and bare areas contributed negatively to SUHI effect. 


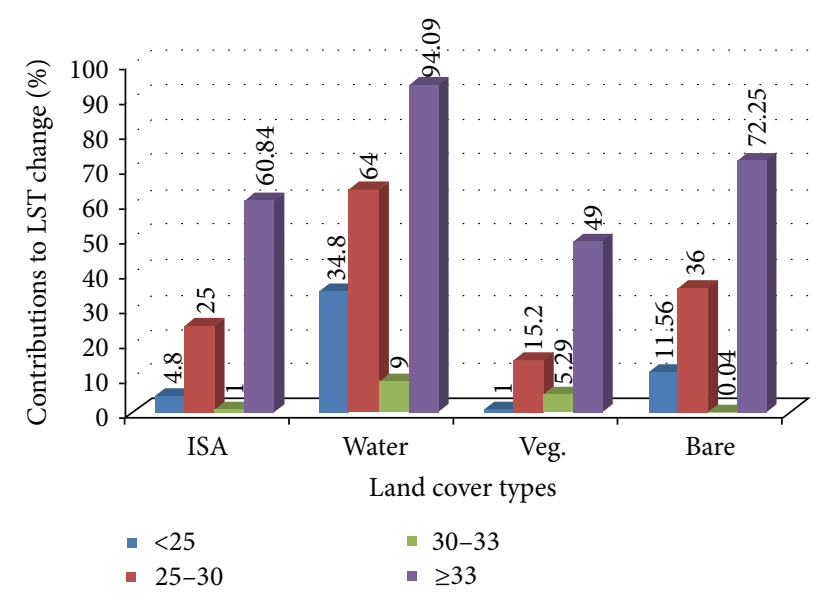

FIgURE 6: Separate contributions of land cover types to surface temperature change.

\section{Conclusion}

In this paper, qualitative and quantitative analyses were performed to study the relationship between land cover changes and SUHIs. The local-scale analyses focused on the city of Abeokuta, and the following conclusions were made: (1) the distribution of surface heat in the urban area of Abeokuta has changed from a mixed pattern to urban heat as the impervious areas expanded rapidly in the city since almost $13 \%$ of the area of the city changed to high LST $\left(\geq 33^{\circ} \mathrm{C}\right.$ ); (2) land cover patterns and changes contributed to the variations in the microclimate and affected the SUHI intensity primarily through an extension of urban core to the rural areas, soil impaction, and deforestation; (3) SUHIs were proportionally related to water bodies $(r=0.97)$ because the slight expansion of the major water body (River Lafenwa) located in the city centre brings about increase in the surface temperature and ISA ( $r=0.78)$ which includes buildings, roads, rock surfaces, parking lots, and other paved surfaces; (4) quantitative analysis among temperature and land cover patterns showed that increasing impervious surface areas will result in LST rise and consequently SUHIs. However, vegetation reduces the LST. Thus, future city planning should focus on urban greening. (5) It is suggested that representative land cover indices can be used together as independent factors in a multiple regression equation model in order to evaluate the effectiveness of land covers as indicators to LST change in a more robust way. Moreover, the change in LST does not fully explain the surface urban heat islands phenomenon as it has been used in this study, but LST is considered one of the important land surface components contributing to surface urban heat. Thus, the calculation of surface urban heat requires data from a comparative geography (e.g., rural versus urban), which was beyond the scope of the study.

\section{Competing Interests}

The authors declare that they have no competing interests.

\section{Acknowledgments}

The authors thank the United States Geological Survey (USGS) for assisting this research with datasets.

\section{References}

[1] Population Division. Department of Economic and Social Affairs. United Nations, World Urbanization Prospects: The 2005 Revision, United Nations, New York, NY, USA, 2006.

[2] A. Chudnovsky, E. Ben-Dor, and H. Saaroni, "Diurnal thermal behavior of selected urban objects using remote sensing measurements," Energy and Buildings, vol. 36, no. 11, pp. 1063-1074, 2004.

[3] Y. Wang, Y. Zhou, and X. Zhang, "The SPLIT and MASC models for extraction of impervious surface areas from multiple remote sensing data," in Remote Sensing of Impervious Surfaces, Q. Weng, Ed., pp. 77-93, CRC Press, Boca Raton, Fla, USA, 2007.

[4] I. Ogashawara and V. S. B. Bastos, "A quantitative approach for analyzing the relationship between urban heat islands and land cover," Remote Sensing, vol. 4, no. 11, pp. 3596-3618, 2012.

[5] X. Zhou and Y.-C. Wang, "Dynamics of land surface temperature in response to land-use/cover change," Geographical Research, vol. 49, no. 1, pp. 23-36, 2011.

[6] T. A. Oke, "The energetic basis of the urban heat island," Quarterly Journal of the Royal Meteorological Society, vol. 108, pp. 1-24, 1982.

[7] F. Yuan and M. E. Bauer, "Comparison of impervious surface area and normalized difference vegetation index as indicators of surface urban heat island effects in Landsat imagery," Remote Sensing of Environment, vol. 106, no. 3, pp. 375-386, 2007.

[8] G. Chander and B. Markham, "Revised Landsat-5 TM radiometric calibration procedures and postcalibration dynamic ranges," IEEE Transactions on Geoscience and Remote Sensing, vol. 41, no. 11, pp. 2674-2677, 2003. 

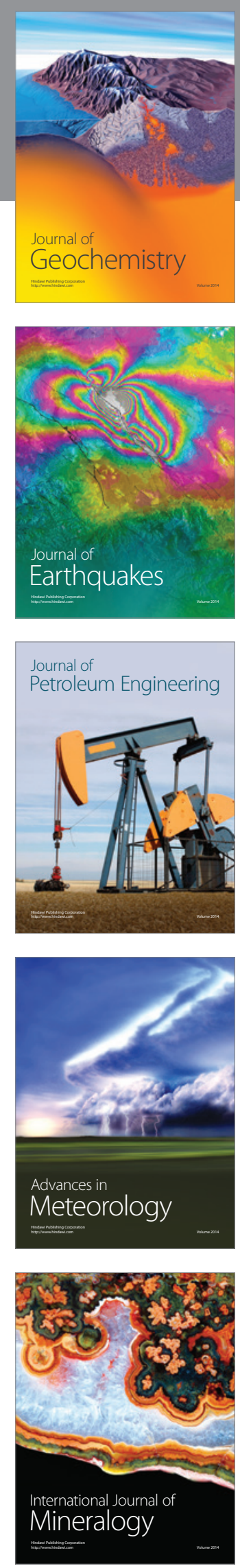
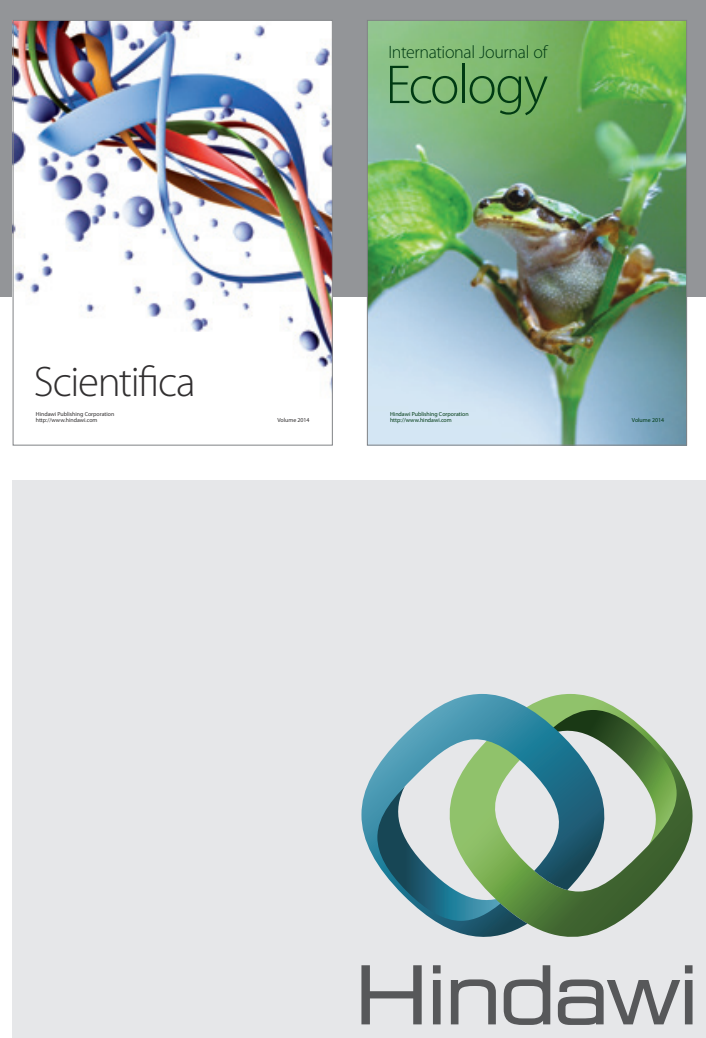

Submit your manuscripts at

http://www.hindawi.com
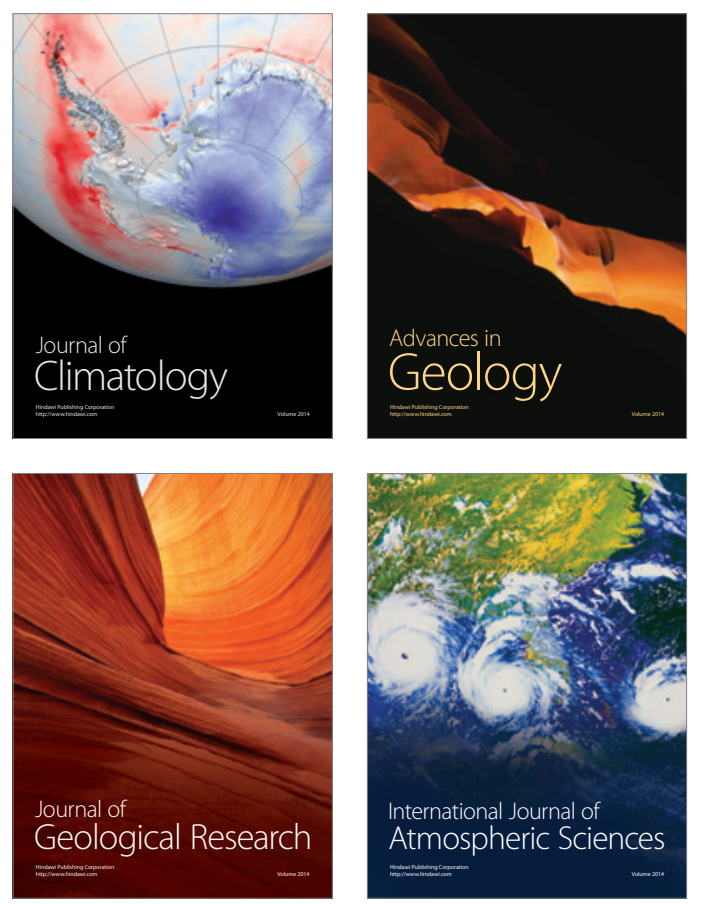

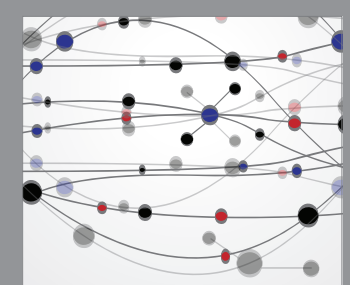

The Scientific

\section{World Journal}
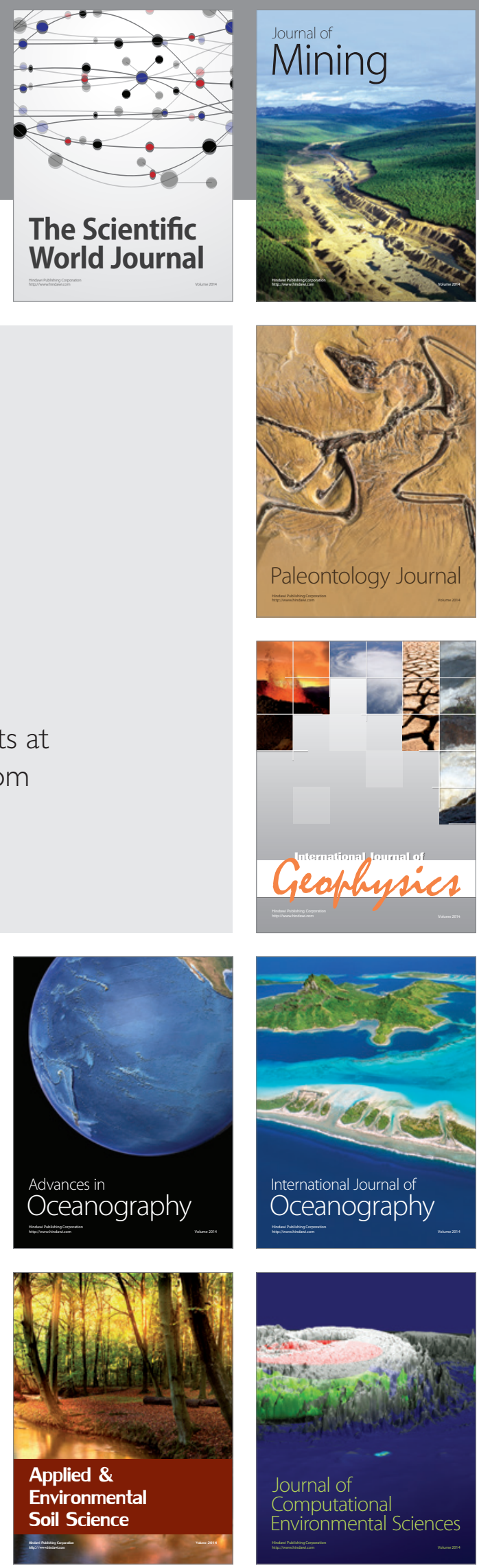